Original Article

\title{
NUMBER NEEDED TO TREAT AS A TOOL FOR COST EFFECTIVENESS ANALYSIS: A CASE STUDY IN RENAL TRANSPLANTATION
}

\author{
POOJA GUPTA', NANDA GAMAD ${ }^{2}$, PRAFULL MOHAN ${ }^{3 *}$ \\ 1Pharmacology, All India Institute of Medical Sciences, New Delhi, ${ }^{2}$ Senior Resident, Pharmacology, Postgraduate Institute of Medical \\ Education and Research, Chandigarh, ${ }^{3}$ Pharmacology, Armed Forces Medical College, Pune \\ Email: prafullcato@yahoo.co.in \\ Received: 13 Jun 2019, Revised and Accepted: 06 May 2020
}

\begin{abstract}
Objective: To assess the utility of number needed to treat (NNT) as a tool for cost effectiveness analysis.

Methods: Two monoclonal antibodies (MAbs), used for induction therapy viz basiliximab and daclizumab in renal transplantation, were identified. Pivotal placebo controlled clinical trials, mentioned in the innovator package inserts, were compared and analyzed for acute graft rejection and graft survival at 12 mo. NNT viz-a-vis cost was calculated and compared.

Results: Daclizumab was comparable to basiliximab for acute graft rejection (NNT 10 vs. 9) but better for graft survival (20 vs. 25) at 12 mo, when used along with triple drug regimen (cyclosporine, azathioprine and corticosteroid). However, considering the cost of regimen for these drugs, in terms of NNT, basiliximab was more cost effective (INR 12,52,044 vs. 28,70,400 for acute rejection and INR 34,77,900 vs. 57,40,800 for graft survival). On the other hand, when these MAbs were used along with dual drug regimen (cyclosporine and corticosteroid), daclizumab was more cost effective for graft survival at 12 mo. The higher cost of daclizumab regimen (INR 2,87,040 vs. 1,39,116 for basiliximab) was offset by its substantially lower NNT ( $20 \mathrm{vs}$. 58-75 for one extra graft survival at $12 \mathrm{mo}$ ).
\end{abstract}

Conclusion: This study demonstrates the utility of NNT in ascertaining relative effectiveness of treatment modalities that would help to formulate appropriate healthcare policies.

Keywords: Number need to treat, Cost effectiveness analysis, Renal transplantation, Daclizumab, Basiliximab, Monoclonal antibodies

(C) 2020 The Authors. Published by Innovare Academic Sciences Pvt Ltd. This is an open access article under the CC BY license (http://creativecommons.org/licenses/by/4.0/] DOI: http://dx.doi.org/10.22159/ijpps.2020v12i6.34578. Journal homepage: https://innovareacademics.in/journals/index.php/ijpps

\section{INTRODUCTION}

World Trade Organization recognizes rational selection and use of medicines as one of the underpinning elements for access to medicines [1]. Reports show that nearly 50-80\% Indian population is not able to access all the medicines that they need as $21.9 \%$ population is below poverty line and $60 \%$ of the total healthcare expenditure is out of pocket by patients themselves [2-4]. According to a World Bank study, large out of pocket medical costs may drive $2.2 \%$ Indian population below the poverty line every year [2]. Clearly, cost of medicine is a big impediment in ensuring its access to the population. More so, new modalities of treatment, including newer drugs, are costlier as compared to their vintage counterparts, and, on top of that, may or may not be equally effective.

Pharmacoeconomics is taken into account by drug regulators of Australia and some other countries before approving new drugs [5]. India approves drugs on the basis of a drug's benefit-risk analysis and uses price capping of essential and certain other medicines. This becomes more significant in light of healthcare infrastructure in India and financial wherewithal of the population. Lack of such pharmacoeconomic consideration not only increases health care cost but the overall disease burden as well. For instance, the annual rate of renal transplantation in India is 3.25 /million population/year, which is far low when compared to the prevalence of end-stage renal disease (ESRD) patients i.e., $150 /$ million population/year. Data shows that $>90 \%$ ESRD patients die within months of diagnosis as this therapy is either not affordable or not accessible [6]. Renal transplant requires long-term treatment with immunosuppressant's to ensure graft survival and prevent graft rejection. Long-term immunosuppressive therapy is not only expensive but has its own adverse effects too [7]. Studies on clinical effectiveness and cost-effectiveness of such drugs might help clinicians to select a drug that is cost-effective and make a difference in the patient outcome by optimizing accessibility [6]. Similar studies have been undertaken for other therapeutic areas and have helped clinicians take the best course in a given situation [8]. However, the awareness regarding principles of pharmacoeconomics is scarce amongst medical professionals and needs to be augmented [9].

Number needed to treat (NNT) is a well-validated and commonly used measure of clinical significance of any intervention. It can be used to assess both advantages and disadvantages between two competing interventions. It is calculated as an inverse of the absolute risk reduction (ARR) due to a treatment modality and represents the number of patients that are required to be treated with a particular modality to prevent one additional target event (graft rejection AND graft survival in the context of this study). Lower NNT means that fewer patients need treatment with the drug for achieving an additional target event [10]. If the target event is a positive outcome, say cure, then the drug with lower NNT is more efficacious. NNT for clinical benefit and harm in respect of different treatment modalities, when juxtaposed with their cost of therapy, becomes a tool for cost-effectiveness analysis [11].

In the present study, with post-transplant use of immunosuppressive drugs as a case in point, cost-effectiveness was evaluated. Two monoclonal antibodies (MAbs) viz basiliximab and daclizumab, recommended for use in patients undergoing renal transplantation to prevent graft rejection, were selected $[12,13]$. These drugs are costly [14] and hence their accessibility is an issue in a resource limited setting. The rising incidence of chronic kidney disease and diabetic nephropathy makes the clinical condition pertinent. NNT was used as a tool to ascertain and compare the clinical effectiveness and costeffectiveness of basiliximab and daclizumab in combination immunosuppressive regimens for renal transplantation.

\section{MATERIALS AND METHODS}

\section{Methods}

The study involved three steps i.e. ascertaining the efficacy of the drug from pivotal clinical trials' data; calculating effectiveness of these drugs using NNT; and establishing cost of therapy based on prevalent market price of these drugs. 


\section{Drug information}

Innovator brands of basiliximab and daclizumab were identified. Package inserts of these innovator brands were analyzed for efficacy and safety data from pivotal clinical trials for licensing. Care was taken to compare only those clinical trials that had similar active comparator group (fig. 1).

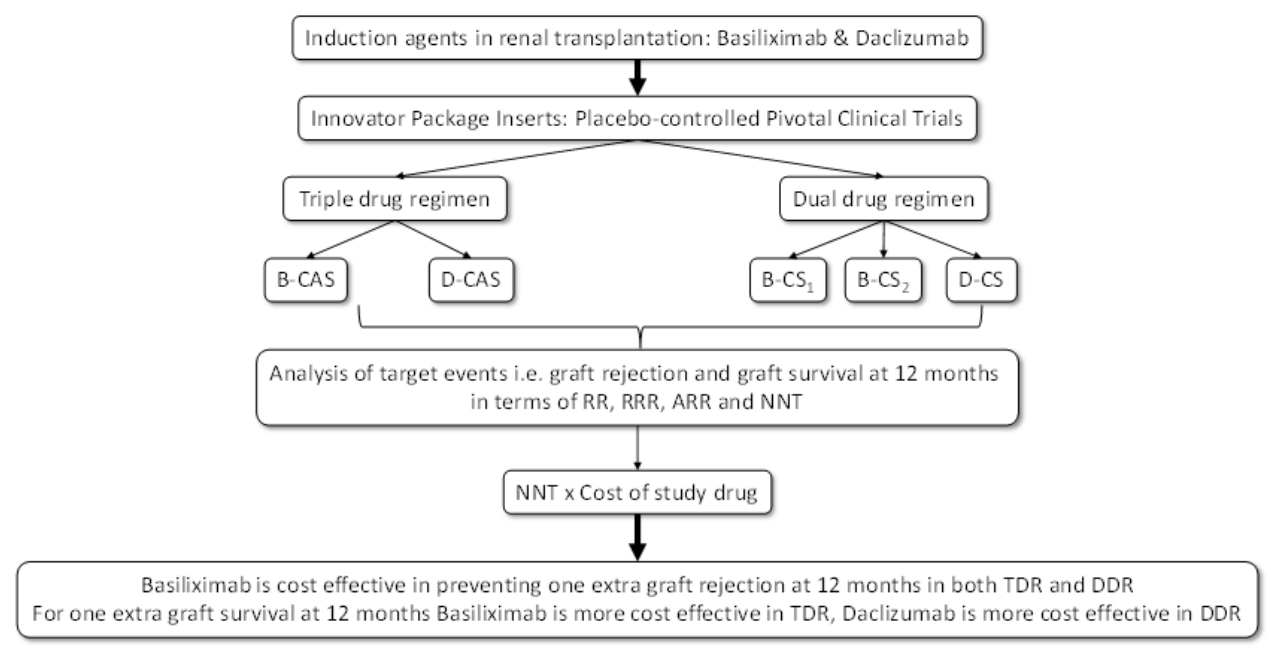

Fig. 1: Study summary, (Relative risk, RRR: relative risk reduction, ARR: absolute risk reduction; NNT: Number needed to treat; B-CAS: Basiliximab, cyclosporine, azathioprine and corticosteroid; D-CAS: Daclizumab, cyclosporine, azathioprine and corticosteroid; B-CS: Basiliximab, cyclosporine and corticosteroid; D-CS: Daclizumab, cyclosporine and corticosteroid)

\section{Pivotal clinical trials on Basiliximab:}

Three trials were reported in the package insert in adults receiving cadaveric-or living-donor renal transplantation.

i) One study compared two $20 \mathrm{mg}$ doses of basiliximab with placebo, both interventions administered in addition to standard immunosuppressive regimens containing cyclosporine, azathioprine and corticosteroid (triple drug regimen, acronym: B-CAS: $\mathrm{n}=172$ in placebo group and $\mathrm{n}=168$ in basiliximab group).

ii) The other two studies compared two $20 \mathrm{mg}$ doses of basiliximab with placebo, both drug administered in addition to immunosuppressive regimens containing cyclosporine and corticosteroids (dual drug regimen, acronym: $\mathrm{B}-\mathrm{CS}_{1}: \mathrm{n}=185$ in placebo group and $\mathrm{n}=190$ in basiliximab group; acronym: $\mathrm{B}-\mathrm{CS}_{2}$ : $\mathrm{n}=173$ in both groups).

In all three studies, first dose of basiliximab or placebo was given within $2 \mathrm{~h}$ prior to transplantation surgery and the second dose was administered on Day 4 post transplantation [13].

\section{Pivotal clinical trials on Daclizumab:}

Two trials compared a dose of $1 \mathrm{mg} / \mathrm{kg} /$ day of daclizumab with placebo in adult patients receiving cadaveric kidney transplant when both interventions (daclizumab and placebo) were administered in addition to standard immunosuppressive regimens containing either:

i) Cyclosporine, azathioprine and corticosteroid (triple drug regimen, acronym: D-CAS: $n=134$ in placebo group and $n=126$ in daclizumab group) OR

ii) Cyclosporine and corticosteroid (dual drug regimen, acronym: D-CS: $n=134$ in placebo group and $n=141$ in daclizumab group).

In both these studies, dosing was initiated within $24 \mathrm{~h}$ pretransplant, with subsequent doses given every $14 \mathrm{~d}$ for a total of five doses [12].

\section{Number needed to treat}

Number needed to treat was used to estimate relative effectiveness of the two study drugs. The calculation of number needed to treat included the following steps:

- Identification of the target events as (i) graft rejection at $12 \mathrm{mo}$ and (ii) graft survival at $12 \mathrm{mo}$
- Extraction of incidence of these target events for basiliximab/daclizumab group and the corresponding placebo group from the selected studies

- Calculation of Absolute Risk Reduction (ARR) as incidence of rejection or survival with placebo group minus the incidence of rejection with basiliximab/daclizumab group

- Number needed to treat (NNT) was calculated as inverse of Absolute Risk Reduction (1/ARR) or

i) Number needed to treat to prevent one graft rejection (NNTr) $=1 /$ (incidence of rejection with placebo group minus the incidence of rejection with drug group).

ii) Number needed to treat to gain one additional graft survival (NNTs) $=1 /$ (incidence of graft survival with drug group minus the incidence of graft survival with placebo group).

Cost of each target event with respect to cost of basiliximab/daclizumab

Cost of individual drug therapy was calculated based on NNTs and total dose regime for daclizumab and basiliximab as follows:

1. Cost of basiliximab/daclizumab required to prevent one additional graft rejection at $12 \mathrm{mo}=\mathrm{NNTr} \mathrm{X}$ no of doses of basiliximab/daclizumab required per patient over 12 mo X cost of a single dose.

2. Cost of basiliximab/daclizumab therapy required to gain one additional graft survival at 12 mo $=$ NNTs $\mathrm{X}$ no of doses of basiliximab/daclizumab required per patient over $12 \mathrm{mo} X$ cost of a single dose.

The average adult dose of basiliximab was considered as $20 \mathrm{mg} /$ day and that of daclizumab as $1 \mathrm{mg} / \mathrm{kg} /$ day, as recommended by FDA. Cost of a single dose was taken from a current commercial drug index in India and drug price listing websites for innovator brands $[15,16]$. With the above data, cost comparison in terms of acute graft rejection and graft survival was carried out between basiliximab and daclizumab.

\section{RESULTS}

\section{Analysis of graft rejection and survival}

In study 1 (B-CAS), the incidence of rejection in basiliximab arm and placebo arm meant that basiliximab led to an ARR of $11 \%$. Besides, 
basiliximab treatment was also able to provide 4 extra graft survivals for every 100 patients in drug treated group (92\%-88\%) during the same 12 mo period.

In study 2 (D-CAS), patients in daclizumab group experienced $28 \%$ of biopsy proven acute rejection in 12 mo while patients in the placebo group experienced 38\% of biopsy proven acute rejection at 12 mo (table 1). Daclizumab group experienced $95 \%$ and placebo group experienced $90 \%$ graft survival at 12 mo. Addition of daclizumab to the standard triple drug regimen (CAS) was thus able to save additional 10 acute rejections (38-28\%) and provide extra 5 graft survival (95-90\%) for every 100 patients at $12 \mathrm{mo}$.

Table 1: Comparison of basiliximab and daclizumab with respect to the target events (acute rejection and graft survival at $12 \mathrm{mo}$ )

\begin{tabular}{|c|c|c|c|c|c|c|c|c|c|c|}
\hline \multirow[t]{2}{*}{ Study } & \multicolumn{5}{|c|}{ Acute rejection (12 mo) } & \multicolumn{5}{|c|}{ Graft survival (12 mo) } \\
\hline & $\begin{array}{l}\text { Incidence } \\
\text { in Placebo } \\
\text { group (\%) } \\
\text { (a) }\end{array}$ & $\begin{array}{l}\text { Incidence } \\
\text { in drug } \\
\text { group } \\
(\%)(b)\end{array}$ & $\begin{array}{l}\text { ARR } \\
(\mathrm{c}=\mathrm{a}- \\
\text { b) } \\
(\%)\end{array}$ & $\begin{array}{l}\text { NNTr } \\
(1 / c \\
\text { X } \\
100)\end{array}$ & $\begin{array}{l}\text { Cost of } 01 \\
\text { additional graft } \\
\text { rejection (NNTr X } \\
\text { drug cost) } \\
\text { (INR) }\end{array}$ & $\begin{array}{l}\text { Inciden } \\
\text { ce in } \\
\text { Placebo } \\
\text { group } \\
\text { (\%) (f) }\end{array}$ & $\begin{array}{l}\text { Incidence } \\
\text { in drug } \\
\text { group } \\
(\%)(g)\end{array}$ & $\begin{array}{l}\text { ARR } \\
\text { (h=g-f) } \\
(\%)\end{array}$ & $\begin{array}{l}\text { NNTs } \\
(1 / h X \\
100)\end{array}$ & $\begin{array}{l}\text { Cost of 01 } \\
\text { additional graft } \\
\text { survival (NNTs } \\
\text { X drug cost) } \\
\text { (INR) }\end{array}$ \\
\hline B-CAS & 30 & 19 & 11 & 9 & $12,52,044$ & 88 & 92 & 4 & 25 & $34,77,900$ \\
\hline D-CAS & 38 & 28 & 10 & 10 & $28,70,400$ & 90 & 95 & 5 & 20 & $57,40,800$ \\
\hline $\mathrm{B}-\mathrm{CS}_{1}$ & 46 & 32 & 14 & 8 & $11,12,928$ & 87 & 88 & 1 & 75 & $1,04,33,700$ \\
\hline B-CS 2 & 49 & 35 & 14 & 8 & $11,12,928$ & 93 & 95 & 2 & 58 & $80,68,728$ \\
\hline D-CS & 49 & 28 & 21 & 5 & $14,35,200$ & 83 & 88 & 5 & 20 & $57,40,800$ \\
\hline
\end{tabular}

B-CAS: Basiliximab, cyclosporine, azathioprine and corticosteroid; D-CAS: Daclizumab, cyclosporine, azathioprine and corticosteroid; B-CS: Basiliximab, cyclosporine and corticosteroid; D-CS: Daclizumab, cyclosporine and corticosteroid; ARR: absolute risk reduction; Number needed to treat i.e. NNTr for acute rejection and NNTs for graft survival at 12 mo; Drug Cost: per patient per year cost of basiliximab =INR 1,39,116 and that of daclizumab =INR 2,87,040; Incidence and ARR have been rounded off to the closest number and NNT has been rounded off to next higher number

Two independent studies on basiliximab versus placebo on top of dual drug regimen showed large variation in acute rejection but relatively less variation in graft survival. In study $3\left(\mathrm{~B}-\mathrm{CS}_{1}\right)$, and study 4 (B-CS2), the ARR for acute rejection was $14 \%$ at $12 \mathrm{mo}$. Though there was $1 \%$ increase in graft survival in study 3 and $2 \%$ increase in study 4 in basiliximab group compared to placebo, the percentage increase in basiliximab group varies, as $88 \%$ and $95 \%$ patients had graft survival in studies 3 and 4 respectively.

In study 5 (D-CS), there was an increased difference in percentage of acute rejections between placebo and drug treated group. Adding daclizumab saved $21(49 \%-28 \%)$ acute rejections for every 100 patients at 12 mo. However, the percentage difference in graft survival was $5 \%$ at $12 \mathrm{mo}$.

\section{NNT for graft survival at 12 mo and NNT for graft rejection at 12 mo}

Study 1 (B-CAS): Basiliximab saved 1 extra acute rejection in every 9 patients at $12 \mathrm{mo}(\mathrm{NNTr}$ at $12 \mathrm{mo}=9)$. NNTs for graft survival at 12 mo was 25 .

Study 2 (D-CAS): Daclizumab had NNT of 10 for acute rejection (NNTr) at 12 mo of treatment. This implies that in order to save 1 additional patient from graft rejection at $12 \mathrm{mo}$, we need to treat 10 patients with daclizumab. Likewise, in order to have 1 extra graft survival at $12 \mathrm{mo}, 20$ patients need to be treated with daclizumab (NNTs at $12 \mathrm{mo}=20$ ).

In study $3\left(\mathrm{~B}-\mathrm{CS}_{1}\right)$, for every 8 patients there was prevention of 1 extra biopsy proven acute rejection with basiliximab at 12 mo as compared to placebo group (NNTr at $12 \mathrm{mo}=8$ ). While in study 4 $\left(\mathrm{B}-\mathrm{CS}_{2}\right), 1$ in every 8 patients benefitted at $12 \mathrm{mo}(\mathrm{NNTr}$ at $12 \mathrm{mo}=$ 8). The NNTs was 75 and 58 for study 3 and 4 respectively (table 1 ).

Study 5 (D-CS): Since NNTr at 12 mo was 5,1 in every 5 patients is likely to be saved from acute rejections at $12 \mathrm{mo}$, if treated with daclizumab-based therapy. Also, daclizumab-based regimen was able to provide 1 extra graft survival for every 20 patients at 12 mo of treatment (NNTs at $12 \mathrm{mo}=20$ ).

\section{Comparison of basiliximab and daclizumab in triple drug regimen}

The per patient cost of therapy for 12 mo in respect of basiliximab and daclizumab was estimated to be Rs 1,39,116 and Rs 2,87,040 respectively, as per the dosing requirements and prevalent cost of innovator's brand.

The triple drug regimen in both the studies (B-CAS and D-CAS) consisted of cyclosporine, azathioprine and corticosteroid. In addition, basiliximab/daclizumab was added in the intervention group and placebo in the comparator group. In order to gain one extra graft survival at $12 \mathrm{mo}, 25$ patients need to be treated with basiliximab-based regimen and 20 patients with daclizumab-based regimen. Accordingly, INR 34,77,900 need to be spent on basiliximab (for 25 patients @ INR 1,39,116/patient/year) and INR 57,40,800 need to be spent on daclizumab (for 20 patients @ INR $2,87,040 /$ patient/year) to gain one extra graft survival over and above the other direct and indirect costs.

Similarly, in order to prevent one extra graft rejection at $12 \mathrm{mo}, 9$ patients need to be treated with basiliximab thereby spending INR $12,52,044 /$-while 10 patients need to be treated with daclizumab by spending INR 28,70,400/-over and above the other direct and indirect costs.

Comparison of basiliximab and daclizumab in dual drug regimen

Cyclosporine and corticosteroids were given in all the studies $\left(\mathrm{B}-\mathrm{CS}_{1}\right.$ $\mathrm{B}^{-} \mathrm{CS}_{2}$ and D-CS). In addition, basiliximab or daclizumab was added in the intervention group vs placebo in the control group. In dual drug regimen, to gain one extra graft survival at $12 \mathrm{mo}, 75$ patients (B$\left.\mathrm{CS}_{1}\right)$ and 58 patients $\left(\mathrm{B}-\mathrm{CS}_{2}\right)$ needed to be treated with basiliximab and 20 patients need to be treated with daclizumab. Therefore, INR $80,68,728 /$-to $1,04,33,700 /$-need to be spent on basiliximab and INR $57,40,800 /$-on daclizumab to gain one extra graft survival at $12 \mathrm{mo}$. Similarly, in order to prevent one extra graft rejection at $12 \mathrm{mo}, 8$ patients need to be treated with basiliximab thereby spending INR 11,12,928/-but 5 patients need to be treated with daclizumab with an expenditure of INR 14,35,200/-over and above the comparator group and other drugs.

\section{DISCUSSION}

In India, nearly $80 \%$ of the tertiary care facilities providing transplant services are available only in the private sector which is out of the financial reach of an average Indian patient [17]. Moreover, health-care insurance coverage is available to $<15 \%$ of the total Indian population [6]. This has reduced the deceased-donation rate to as low as 0.08 per million population per year [18].

Basiliximab and Daclizumab are IgG1 MAbs against interleukin-2 receptor (CD25 antigen). Pivotal clinical trials show that induction therapy with basiliximab in two doses or daclizumab in five doses reduces the incidence of acute rejection and improves the chances of graft survival $[12,13]$. However, pharmacoeconomic analysis of these clinically effective drugs is needed to select the more costeffective option of the two for poorer populations and especially in 
countries like India. A concern often expressed by cost-effectiveness analysis researchers is that the results are not consistently implemented in practice settings because of the inability to conceptualize health economic measures and lack of relevance to clinical settings [11].

If target events (such as graft rejection and graft survival) are presented along with economic end points (such as amount spent to prevent one acute rejection or to gain one graft survival), it is likely to improve understanding of health economic evidence by clinical decision-makers [11]. NNT is a useful absolute measure of treatment effect that expresses its magnitude in a clinically useful way. While the statistical significance of trial outcome denotes whether or not the result could have arisen by chance, NNT determines how frequently the outcome can be expected in a day-to-day clinical practice [11]. Therefore the concept of NNT is intuitively easy to comprehend and can also help in communicating this issue to patients. However, NNT can only be calculated for binary outcomes.

In the present study, NNT was used as a tool to assess both clinical effectiveness and cost-effectiveness of basiliximab and daclizumab. Firstly the clinical effectiveness of study drugs was compared and then cost-effectiveness analysis was carried out. In triple drug regimen (cyclosporine, azathioprine and corticosteroid), daclizumab was comparable to basiliximab for acute graft rejection (NNTr 10 vs. 9) at 12 mo but better for graft survival (NNTs 21 vs. 31) at 12 mo. However, considering the cost of regimen for these drugs in terms of NNT, basiliximab was found to have better cost effectiveness as compared to daclizumab.

On the other hand, when these MAbs were used along with dual drug regimen, (cyclosporine and corticosteroid), daclizumab was more cost effective for graft survival at $12 \mathrm{mo}$. The higher cost of daclizumab was offset by its substantially lower NNT (20 vs. 58-75 for one extra graft survival at $12 \mathrm{mo}$ ). A US cost-effectiveness study comparing daclizumab to placebo suggested that daclizumab is cost-effective at $10 \mathrm{y}$ but not at $1 \mathrm{y}$, in terms of graft survival. Another study compared basiliximab to placebo and reported that basiliximab is cost-effective for graft survival at both 1-year and 10-year [19]. However, there are no head-on trials comparing basiliximab and daclizumab which makes selection of one drug difficult.

There are some limitations in the present study. It includes only limited clinical trial data mentioned in the package insert wherein type of rejection is not mentioned; and only acute graft rejection and graft survival are considered in the study, setting aside other events that decide medical care. Cost of treating acute graft rejection has been taken as a constant, and therefore it has not been included in cost analysis. However, this cost varies from place to place. Head on comparative trial between basiliximab and daclizumab has not been carried out. However, care has been taken to include only those trials that had same comparator groups. We have reported only the point estimates for NNT and not its confidence interval(s) as it was imperative to use one single number so as to derive the cost of therapy for cost effectiveness analysis.

Despite these limitations, our study demonstrates the utility of NNT in ascertaining relative cost effectiveness of treatment modalities. Such analysis needs to be undertaken on a large scale, taking maximum possible clinical data, so as to formulate appropriate policies that take due cognizance of economic aspects of therapeutic decision-making. Further, this ex ante evaluation requires field testing and ex post evaluation of incremental cost effectiveness ratio.

\section{CONCLUSION}

Use of NNT in cost-effectiveness analysis is a contemporary development. Besides, clinical relevance of a statistically significant result in the trial can be evaluated for likelihood of it getting encountered in day-to-day practice. This study demonstrates the utility of NNT in ascertaining relative cost effectiveness of treatment modalities that would help to formulate appropriate healthcare policies.

\section{ACKNOWLEDGEMENT}

The authors gratefully acknowledge the inputs from Dr Arun Kumar Yadav, PhD Scholar in Clinical Epidemiology at our institute.

\section{FUNDING}

Nil

\section{AUTHOR CONTRIBUTIONS}

All authors contributed equally

\section{CONFLICT OF INTERESTS}

\section{Declared none}

\section{REFERENCES}

1. World Trade Organization. Promoting access to medical technologies and innovation. Intersections between public health, intellectual property and trade. Switzerland: WTO Publications; 2013. Available from: http://www.wto.org/english/res_e/booksp_e/pamtiwhowipo wtoweb13_e.pdf [Last accessed on 20 Jan 2019]

2. Sengupta A, Joseph RK, Modi S, Syam N. Economic constraints to access to essential medicines in India. Delhi: progressive printers. New Delhi Society for Economic and Social Studies, Centre for Trade and Development; 2008.

3. Planning Commission. Press Note on Poverty Estimates, 201112. Government of India, Planning Commission. New Delhi: Press information bureau; 2013. Available from: http://planningcommission.nic.in/news/pre_pov2307.pdf [Last accessed on 05 May 2019]

4. Sinha K. India ranks 3rd in region in 'out of pocket' med spend. The Times of India; 2012. Available from: http://timesofindia.indiatimes.com/india/India-ranks-3rd-inregion-in-out-of-pocketmedspend/articleshow/13178290.cms. [Last accessed on 09 Dec 2018]

5. Holden WL. Benefit-risk analysis a brief review and proposed quantitative approaches. Drug Saf 2003;26:853-62.

6. Abraham G, Reddy YNV, Reddy YNV, Shroff S, Mathew M, Sarvanan S. Evolution of deceased-donor transplantation in India with decline of commercial transplantation: a lesson for developing countries [Meeting Report]. Kidney Int Suppl 2013;3:190-4.

7. Tanriover B, Stone PW, Mohan S, Cohen DJ, Gaston RS. Future of medicare immunosuppressive drug coverage for kidney transplant recipients in the United States. Clin J Am Soc Nephrol 2013;8:1258-66.

8. Gopi B, Sushmitha C, Nikitha KSV, Monika M, Gunda RK, Satyanarayana $\mathrm{V}$, et al. Cost-effectiveness analysis in the management of stroke. Asian J Pharm Clin Res 2017;10:127-30.

9. Tabassum R, Hussain SS, Banday M. Evaluation of pharmacoeconomics awareness and its application among postgraduates of a tertiary care hospital: a cross-sectional observational study. Asian J Pharm Clin Res 2016;9:145-7.

10. Citrome L. Compelling or irrelevant? Using number needed to treat can help decide. Acta Psychiatr Scand 2008;117:412-9.

11. Garg V, Shen X, Cheng Y, Nawarskas JJ, Raisch DW. Use of number needed to treat in cost-effectiveness analyses. Ann Pharmacother 2013;47:380-7.

12. Zenapax [package insert]. Nutley (NJ): Hoffmann-La Roche Inc; 2005. Available from: http://www.accessdata.fda.gov/ drugsatfda_docs/label/2005/103749s5059lbl.pdf. [Last accessed on 20 Jan 2019]

13. Simulect [package insert]. East Hanover (NJ): Novartis Pharmaceuticals Corp; 2003. Available from: http://www.accessdata.fda.gov/drugsatfda_docs/label/2003/ basnov010203LB. htm [Last accessed on 14 Dec 2017]

14. Pascual J, Marcean R, Ortunao J. Anti-interleukin-2 receptor antibodies: basiliximab and daclizumab. Nephrol Dial Transplant 2001;16:1756-60.

15. Concise Prescribing Information of: SIMULECT. CIMS; 2014 Available from: http://www.mims.com/India/drug/info/SIMULECT/SIMULECT $\% 20$ powd\%20for\%20inj?type=brief [Last accessed on 04 Jan 2018].

16. DrugsUpdate.com. Brand Index Filter; 2011. Available from: http://www.drugsupdate.com/brand/filter/Z/14 [Last accessed on 04 Jan 2018]. 
17. Abraham G, John GT, Shroff S, Fernando EM, Reddy YNV. Evolution of renal transplantation in India over the last four decades. NDT Plus 2010;3:203-7.

18. Khanna P. The economics of dialysis in India. Indian J Nephrol 2009;19:1-4
19. Woodroffe R, Yao GL, Meads C, Bayliss S, Ready A, Raftery J, et al. Clinical and cost-effectiveness of newer immunesuppressive regimens in renal transplantation: a systematic review and modelling study. Health Technol Assess 2005;9:1179 